\title{
Research on solute transport characteristics in the process of artificial recharge to control land subsidence in deep confined aquifer
}

\author{
Jianzhong $\mathbf{W u} \mathbf{u}^{1,2,3}$, Xuexin Yan ${ }^{1,2,3}$, Tianliang Yang ${ }^{1,2,3}$, and Xinlei Huang ${ }^{1,2,3}$ \\ ${ }^{1}$ Key Laboratory of Land Subsidence Monitoring and Prevention, \\ Ministry of Land and Resources, Shanghai, 200072, China \\ ${ }^{2}$ Shanghai Institute of Geological Survey, Shanghai, 200072, China \\ ${ }^{3}$ Shanghai Engineering Research Center of Land Subsidence, Shanghai, 200072, China \\ Correspondence: Jianzhong Wu (wujianzhong@sigs.com.cn)
}

Published: 22 April 2020

\begin{abstract}
Since 1960s, Artificial Recharge has been adopted to control the geological disaster of land subsidence in Shanghai. The water source to recharge to the confined aquifer meet the Standard for Drinking Water Quality which comes from the Huangpu River or Yangtze River. Thinking the difference between the primary environment of deep confined aquifer and the surface water, the recharge will exert an impact on the quality of groundwater in the deep confined aquifer, as well as to obtain satisfactory effects of land subsidence prevention.This paper focused on the change rules of the elements such as $\mathrm{Cl}$ based on long term tracking and monitoring data from one artificial recharge testing field. And research the solute transport characteristics in deep confined aquifer during artificial recharge. On the bases of these analysis, this paper presented the degree and scope of influence to deep confined aquifer in the process of artificial recharge.
\end{abstract}

\section{Background}

Land subsidence is the major geological disaster in Shanghai. For more than half a century, land subsidence has caused significant changes in Shanghai's regional geomorphology. At present, the elevation of central urban area is generally less than $3.5 \mathrm{~m}$. The characteristics and trend of land subsidence in Shanghai have been developing continuously with the adjustment of groundwater exploitation and artificial recharge pattern and the urban development process. Since 1966, a number of land subsidence control measures were adopted, the land subsidence development trend has been gradually alleviated.

Land subsidence in Shanghai area is mainly caused by the excessive exploitation of groundwater resources in the past ( $\mathrm{Li}$ and Wang, 2006). The Quaternary loose strata in the area are composed of unconsolidated clay, sand and gravel, which inter-bedded or inter-stratified, and contain rich confined groundwater in the sand and gravel layers.
The total pressure of the soil layer above the confined aquifer is an equilibrium with the pressure between the particles in the soil layer and the pore water pressure in the particle pores of the soil layer (Bouwer, 2002). When excessive pumping of groundwater from confined aquifers occurs, the water level of the aquifer decreases significantly and the pore water pressure decreases accordingly, resulting in compaction of the aquifer. At the same time, hydraulic gradient is generated between confined aquifer and overlying clay, which reduces pore water pressure in clay layer.Under the condition that the total pressure of the upper soil layer remains unchanged, the pressure borne by the soil particles increases correspondingly, resulting in further consolidation and compression of the soil layer. The common action of these factors causes land subsidence on the ground (Wei, 2002)

Therefore, artificial recharge groundwater is adopted in Shanghai area to promote the rapid rise of groundwater level and artificially increase the water head pressure in the aquifer, which results in the rebound of the water-bearing 
Table 1. Parameters of Monitoring and Injection Wells.

\begin{tabular}{lrrrrr}
\hline Well & $\begin{array}{r}\text { Distance to } \\
\text { injection Well (m) }\end{array}$ & $\begin{array}{r}\text { Diameter of } \\
\text { Well }(\mathrm{mm})\end{array}$ & $\begin{array}{r}\text { Elevation of } \\
\text { Aquifer }(\mathrm{m})\end{array}$ & $\begin{array}{r}\text { Elevation of } \\
\text { Filter }(\mathrm{m})\end{array}$ & $\begin{array}{r}\text { Specific Yield } \\
\left(\mathrm{m}^{3}(\mathrm{~h} \mathrm{~m})^{-1}\right)\end{array}$ \\
\hline J1 & 42 & 219 & -163.93 to -217.75 & -190.57 to -210.57 & 26.42 \\
J2 & 76 & 219 & -165.41 to -215.41 & -190.91 to -210.91 & 26.00 \\
J3 & 139 & 219 & -162.92 to -216.92 & -190.42 to -210.42 & 36.39 \\
J4 & 10 & 219 & -163.23 to -216.17 & -190.48 to -210.48 & 27.17 \\
J5 & 17 & 219 & -163.62 to -229.02 & -190.62 to -210.62 & 27.73 \\
J6 & 31 & 219 & -165.48 to -216.98 & -190.48 to -210.48 & 26.00 \\
J7 & 56 & 219 & -165.10 to -216.10 & -190.60 to -210.60 & 23.60 \\
J8 & 100 & 219 & -164.71 to -213.21 & -189.81 to -209.81 & 32.86 \\
J9 & 180 & 219 & -164.16 to -217.45 & -190.67 to -210.67 & 23.14 \\
J10 & 475 & 219 & -163.44 to -216.90 & -190.34 to -210.34 & 35.12 \\
Injection & & 325 & -165.53 to -214.03 & -190.63 to -210.63 & 52.00 \\
\hline
\end{tabular}

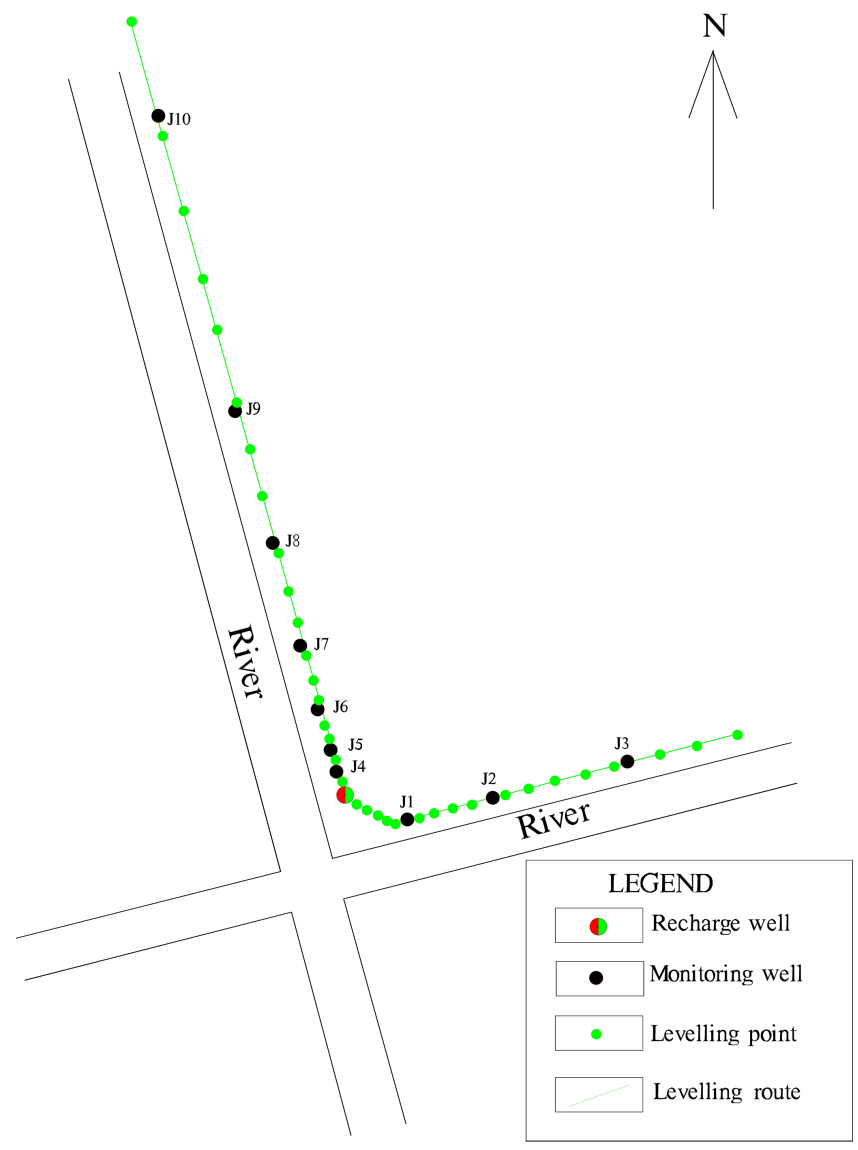

Figure 1. Plan of Recharge Testing Site.

sand layer. At the same time, the upper clay layer is filled with a lot of water, the pore water level rises, and the cohesive soil expands. The superposition of the rebound of sand layer and the expansion of cohesive soil results in the rebound of the ground.

\section{General situation of artificial recharge testing site}

In order to study the environmental impacts and land subsidence induced by artificial groundwater recharge, a fourth confined aquifer groundwater artificial recharge testing site had been constructed in the north of Shanghai, which contained 1 injection Wells, 10 monitoring Wells and land subsidence monitoring points. The groundwater monitoring Wells and the layout of two section of land subsidence monitoring, parallel to and perpendicular to the groundwater streamline respectively (Figs. 1, 2, Table 1).

The testing site is located at the side beach of the LiuNan ancient channel. The thickness of the fourth confined aquifer is about $30.0-37.8 \mathrm{~m}$, and the elevation of the aquifer top surface is -162.92 to $-165.53 \mathrm{~m}$. The lithology mainly consists of dark gray

medium fine sand and local medium coarse sand. The water conductivity coefficient of this aquifer in the test site area is about $692-1124 \mathrm{~m}^{2} \mathrm{~d}^{-1}$, and the specific yield of a single well is $23.60-52.00 \mathrm{~m}^{3}(\mathrm{~h} \mathrm{~m})^{-1}$. In addition, the groundwater level of this aquifer is rising year by year with the decrease of groundwater exploitation in Shanghai.

Since August 2012, artificial recharge was started, and the initial injection flow quantity was about $16.1 \mathrm{~m}^{3} \mathrm{~h}^{-1}$. After that, the continuous injection flow quantity was about $35.1 \mathrm{~m}^{3} \mathrm{~h}^{-1}$, and the cumulative injection volume exceeded $240000 \mathrm{~m}^{3}$ (Fig. 3).In the process of recharge, groundwater recharge quantity, groundwater level and underground water quality had been monitored continuously.

\section{Effect of artificial recharge on land subsidence control}

\subsection{Ground water level}

Can be seen from the curve of groundwater level shown by monitoring well J4 and J9 (Fig. 4) that the groundwater level around the recharge well gradually rises and tends to 


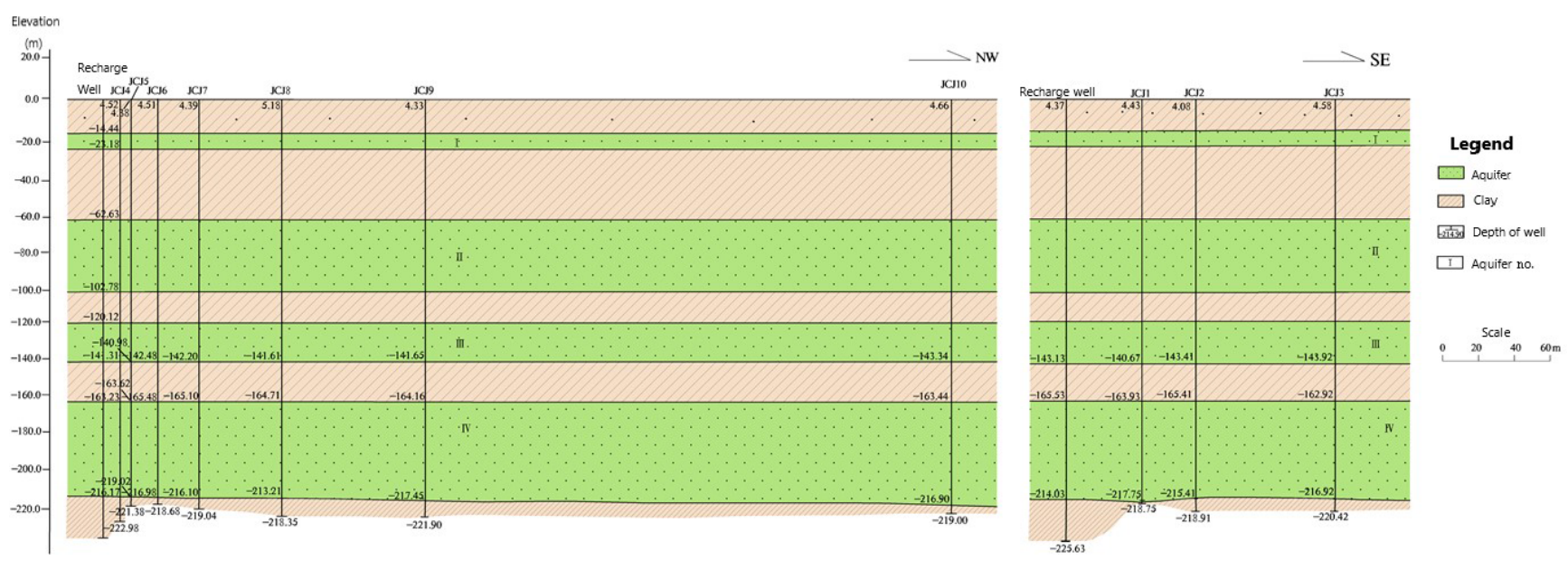

Figure 2. Geological section of recharge testing site.

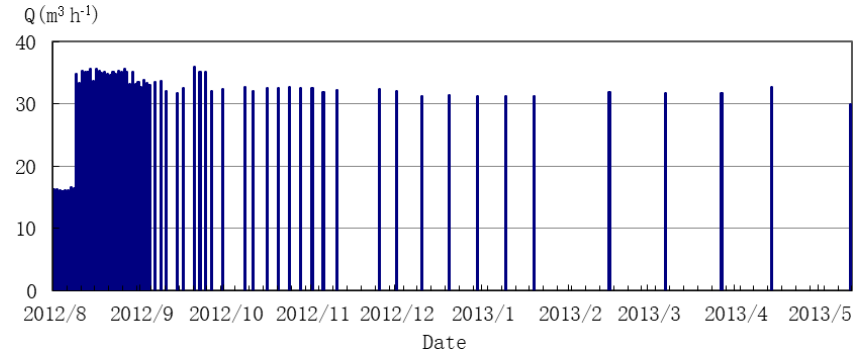

Figure 3. Rate of injection curve in the testing site.

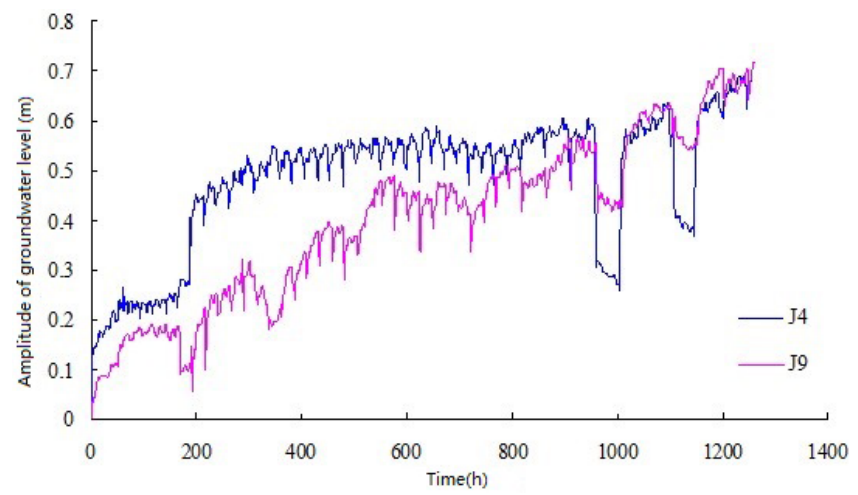

Figure 4. Groundwater lever curve of J4 and J9 during recharging.

be stable after the recharge test begins. After increasing the recharge, the groundwater level rises further, and the maximum uplift of $\mathrm{J} 4$ and $\mathrm{J} 9$ monitoring Wells reaches $0.65 \mathrm{~m}$.

\subsection{Land subsidence}

The surface subsidence monitoring profile on the north and east sides of the recharge test site (Fig. 5) shows that after $323 \mathrm{~d}$ of artificial recharge of the fourth confined aquifer, the maximum surface rebound of the test site area reaches
$11.1 \mathrm{~mm}$ which located $75 \mathrm{~m}$ away from the recharge well. Generally, the rebound of the test site area is about $4-8 \mathrm{~mm}$.

\section{Analysis of solute transport under artificial recharge}

Chloride ions neither form insoluble minerals nor are adsorbed by colloids, so it is called the most stable ions in groundwater and are often used as tracers to indicate the speed of water flow.

\subsection{Transport law of $\mathrm{Cl}^{-}$migration}

The concentration of chloride ion in the groundwater of the test site is about $315 \mathrm{mg} \mathrm{L}^{-1}$, and the recharging water is about $25 \mathrm{mg} \mathrm{L}^{-1}$, with a large difference between the two concentrations. Therefore, the change of chloride ion concentration can reflect the flow movement and the mixing degree of the recharging water and the original groundwater. As can be seen from Fig. 6, the chloride ion of $\mathrm{J} 4$ was significantly reduced at $0.5 \mathrm{~d}$ from the beginning of the recharge experiment, and the chloride ion concentration was close to the recharge water source at $9 \mathrm{~d}$ from the recharge, indicating that the mixing of the two water sources continued.The chloride ion concentration of $\mathrm{J} 5$ showed a decreasing trend $2 \mathrm{~d}$ after the beginning of injection, which was weaker than that of J4. Monitoring well J6 showed a downward trend $12 \mathrm{~d}$ after the beginning of recharge, indicating that the recharge water source migrated to the location of J6 and approached the recharge water source $60 \mathrm{~d}$ after the recharge. With the progress of recharge, the decrease of hydraulic gradient leads to the increase of resistance, resulting in the flow movement slowing down with the increase of distance. After $323 \mathrm{~d}$ of recharge test, the chloride ion concentration in $\mathrm{J} 8 \mathrm{mon}$ itoring well, which is $100 \mathrm{~m}$ away from the recharge well, still showed no significant downward trend, indicating that 

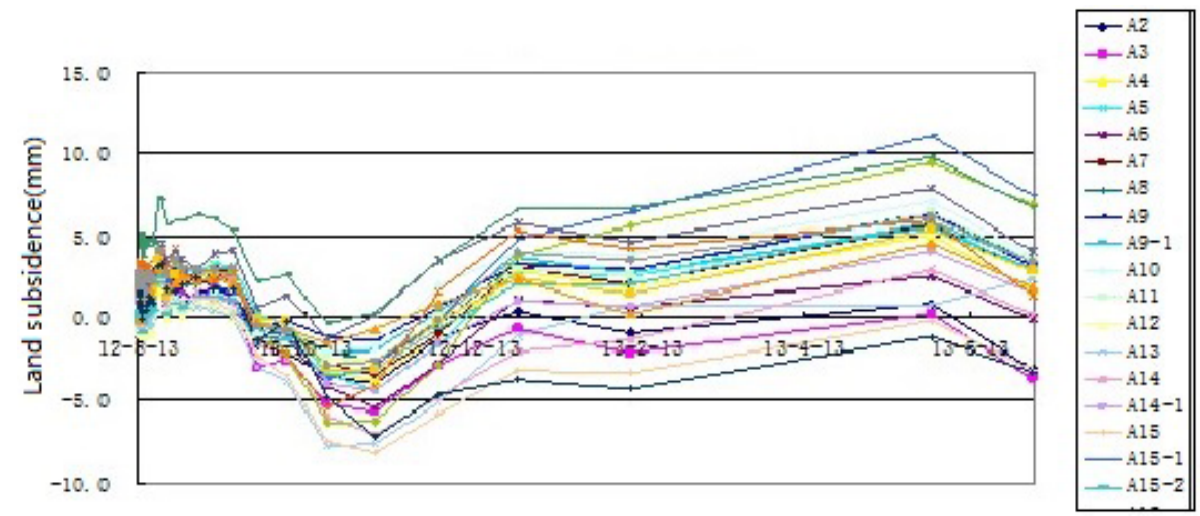

Figure 5. Land subsidence curve during rechaging.

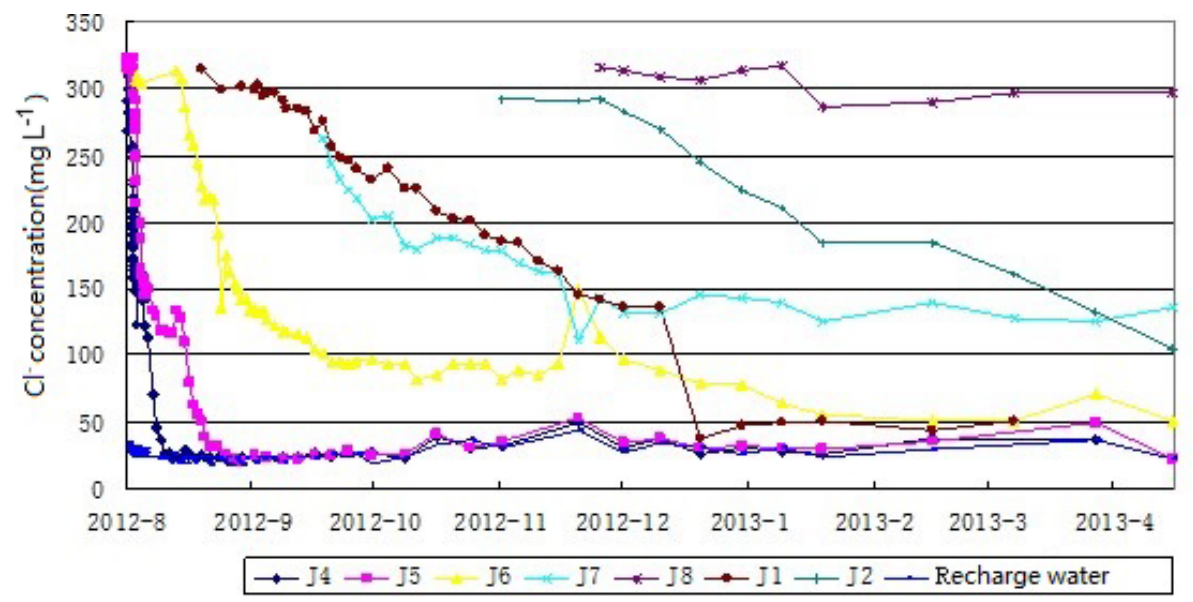

Figure 6. Concentration of $\mathrm{Cl}^{-}$curve in groundwater during recharging.

the recharge had no impact on groundwater quality beyond $100 \mathrm{~m}$.

\subsection{Diffusion rate}

The diffusion rate of groundwater can be judged according to the variation of $\mathrm{Cl}^{-}$ion concentration in monitoring Wells. Table 2 shows the diffusion rate under the condition of each monitoring Wells according to $\mathrm{Cl}^{-}$ion concentration obvious changes in groundwater diffusion rate of interval calculations, it can be seen that $\mathrm{Cl}^{-}$ion migration rate as monitoring spacing decreases with the increase of recharge well distance.The diffusion rate is inversely proportional to the distance between the monitoring well and the recharge well. The farther the distance from the recharge well is, the smaller the dispersion rate is. This is mainly because the farther the distance from the recharge well is, the smaller the hydraulic gradient caused by the recharge well is, and the smaller the ion dispersion rate is, indicating that the diffusion rate is mainly controlled by the groundwater flow field.
Table 2. $\mathrm{Cl}^{-}$ion diffusion rate of each monitoring well.

\begin{tabular}{lrr}
\hline $\begin{array}{l}\text { Monitoring } \\
\text { Well No. }\end{array}$ & $\begin{array}{r}\text { Distance to } \\
\text { Recharge Well (m) }\end{array}$ & $\begin{array}{r}\text { Migration Rate } \\
\left(\mathrm{m} \mathrm{d}^{-1}\right)\end{array}$ \\
\hline J4 & 10 & 20 \\
J5 & 17 & 8.5 \\
J6 & 31 & 2.2 \\
J1 & 42 & 1.2 \\
J7 & 56 & 1.2 \\
J2 & 76 & 0.8 \\
J8 & 100 & 0.6 \\
\hline Average & - & 4.92 \\
\hline
\end{tabular}

\subsection{Radial characteristics of solute transport}

The groundwater diffusion transition zone formed by single well recharge presents a series of concentric circles (Fig. 7), and the influence radius and width of the dispersion zone are approximately equal in all directions. The results indicate that the water quality diffusion of single well recharge in an ap- 


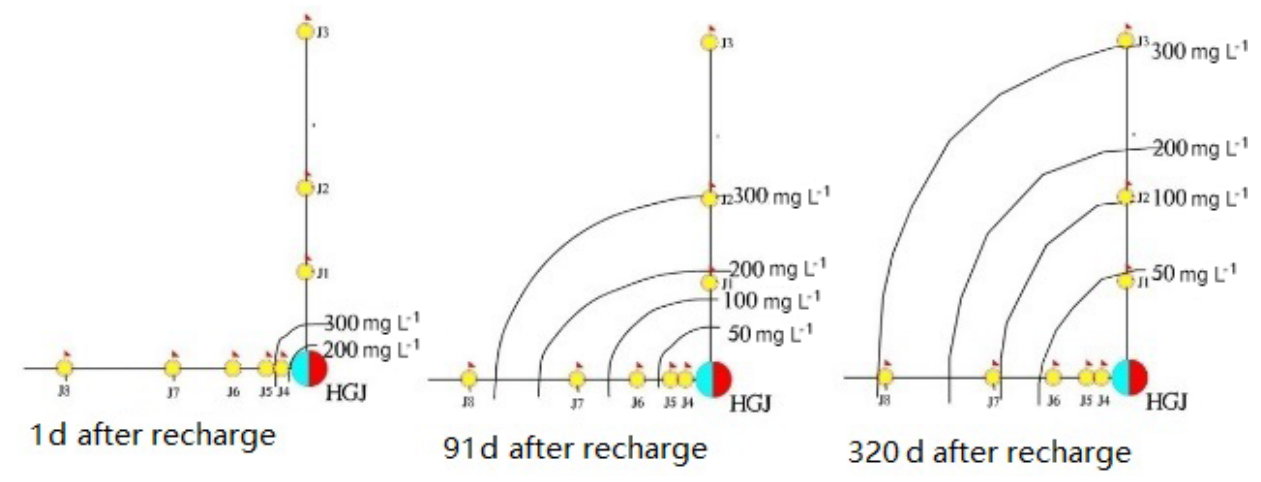

Figure 7. Radial distribution characteristics of $\mathrm{Cl}^{-}$ion diffusion.

proximately isotropic aquifer is in concentric circles and diffuses far away, and the main factor affecting its migration rate is the groundwater flow field.

\section{Conclusions}

Based on the results, the following conclusions can be drawn:

1. Artificial groundwater recharge has certain effect on raising groundwater level and controlling land subsidence. In a short period of time, the surface around the recharge well can rebound. During the test, the rebound During the recharge test, the maximum rebound of the surrounding ground of the recharge well was more than $10 \mathrm{~mm}$.

2. During the process of recharge, the concentration of $\mathrm{cl}^{-}$ and other ion in groundwater decreases gradually and tends to be stable. The influence area is concentric circles with the recharge well as the center.

3. Artificial recharge has a limited influence on groundwater quality, which can be seen from the monitoring results of recharge experiment that the influence range is less than $100 \mathrm{~m}$.

Data availability. All the geological environment monitoring data can be found in the website: http://www.sigs.com.cn/sigsonlines/ (last access: 6 March 2020). At the same time, all data generated or used during the study appear in this article.

Author contributions. JW did the formal analysis and wrote the paper. XY and TY were responsible for the conceptualization and supervision of the project. XH did part of the data acquisition and analysis.

Competing interests. The authors declare that they have no conflict of interest.
Special issue statement. This article is part of the special issue "TISOLS: the Tenth International Symposium On Land Subsidence - living with subsidence". It is a result of the Tenth International Symposium on Land Subsidence, Delft, the Netherlands, 17-21 May 2021.

Acknowledgements. This is a contribution of the IGCP-663 project "Impact, Mechanism, Monitoring of Land Subsidence in Coastal cities" of the IUGS and UNESCO. The authors appreciate the financial support provided by the Shanghai Science and Technology Commission (No. 18DZ1201100) for this work.

Financial support. This research has been supported by the International Geoscience Programme (grant no. IGCP 663) and the Shanghai Science and Technology Commission (grant no. 18DZ1201100).

\section{References}

Bouwer, H.: Artificial recharge of groundwater: hydrogeology and engineering, Hydrogeol. J., 10, 121-142, 2002.

Li, Q. and Wang, H.: Research on land subsidence of Shanghai, College Geology Journal, 2, 169-178, 2006 in Chinese with English abstract).

Wei, Z.: Analysis on stress-strain relationship of the fourth aquifer in Shanghai, Hydrogeology and Engineering Geology, 1, 1-4, 2002 (in Chinese with English abstract). 